\title{
Comparison of Quality of Life and Sexuality between Cervical Cancer Survivors and Healthy Women
}

\author{
Yumi Lee, $\mathrm{RN}, \mathrm{PhD}{ }^{1}$ \\ Myong Cheol Lim, MD, PhD $1,2,3$ \\ Se lk Kim, MD ${ }^{4}$ \\ Jungnam Joo, $\mathrm{PhD}$ 3,5 \\ Dong Ock Lee, MD, $P D^{1}$ \\ Sang-Yoon Park, MD, PhD',2
}

${ }^{1}$ Center for Uterine Cancer, ${ }^{2}$ Gynecologic Cancer Branch, Research Institute and Hospital,

${ }^{3}$ Department of Cancer Control,

Graduate School of Cancer Science and Policy,

National Cancer Center, Goyang,

${ }^{4}$ Department of Obstetrics and Gynecology,

Seoul National University

College of Medicine, Seoul,

${ }^{5}$ Biometric Research Branch,

Research Institute and Hospital,

National Cancer Center, Goyang, Korea

\section{Purpose}

The purpose of this study is to compare quality of life $(\mathrm{QoL})$ and sexual functioning between sexually active cervical cancer survivors and healthy women.

\section{Materials and Methods}

In this cross-sectional study, propensity-score-matched cervical cancer survivors ( $n=104)$ and healthy women $(n=104)$ were compared. All women had engaged in sexual activity within the previous 3 months, and cervical cancer survivors showed no evidence of disease after primary treatment. QoL and sexual functioning were assessed using three questionnaires; the European Organization for Research and Treatment of Cancer Quality of Life Questionnaire Core 30 (EORTC QLQ-C30), Cervical Cancer Module (EORTC QLQ-CX24), and the Female Sexual Function Index (FSFI).

\section{Results}

Significantly higher scores for lymphedema were observed in the cervical cancer survivors group compared with the healthy women group (mean, 20.2 vs. 12.2; $p<0.05$ ). Sexuality, both in terms of sexual activity, sexual enjoyment, and sexual worry (EORTC QLQ-CX24), and in terms of desire, arousal, lubrication, orgasm, satisfaction, and pain (FSFI) were similar between the groups. When the scale of sexual/vaginal functioning in EORTC QLQ-CX24 was divided into individual questions, cervical cancer survivors reported shorter vaginal length than the control group, but without statistical significance (mean, 80.6 vs. 85.4; $p=0.077$ ).

\section{Conclusion}

Compared with healthy women, sexuality was not impaired in cervical cancer survivors who showed no evidence of disease after primary treatment and engaging in sexual activity. Further prospective cohort studies are warranted to confirm this finding.

National Cancer Center, 323 Ilsan-ro,

Ilsandong-gu, Goyang 10408, Korea

Tel: 82-31-920-1760

Fax: 82-31-920-1238

E-mail: gynlim@gmail.com

Received November 5, 2015

Key words

Accepted January 22, 2016

Published Online February 12, 2016

\section{Introduction}

In 2015, cervical cancer was predicted to account for 2.2\% of all new cancers $(n=3,100)$ and $2.6 \%$ of all cancer deaths $(\mathrm{n}=761)$ among Korean women [1]. The incidence of cervical cancer is much higher than that of other gynecologic malignancies such as endometrial cancer and ovarian cancer [2]. As the recent survival of cervical cancer patients has improved, quality of life (QoL), including sexuality, has become an important issue for survivors [3]

Reports on sexuality in Korean women have been limited [4-6]. For women with gynecologic cancer, survivors' QoL and sexual functioning worsened after treatment $[3,7]$. Treatment for cervical cancer is composed of radiotherapy, chemotherapy, and radical surgery, and various combinations of these modalities are frequently administered. Considering these aspects, some studies have evaluated the extent of deterioration according to the type of treatment [8]. However, small size of the study population, heterogeneity 
in patient's characteristics, and use of different questionnaires among the studies hinder inferences from the results. In addition, it is necessary to measure cervical cancer survivors' sexuality using authorized questionnaire sets and to perform a comparison with that of a proper control group.

Sexual-wellbeing is an important part of cancer survivorship. Therefore, precise information on this issue, which might be affected by treatment, should be provided to cancer survivors as well as to their partners. Thus, the aim of this study was to compare QoL and sexual functioning between cervical cancer survivors and healthy women.

\section{Materials and Methods}

After obtaining approval from the Institutional Review Board (NCCNCS-13-685), the current study was conducted in the outpatient clinic of the National Cancer Center, Korea during the period between February 2013 and January 2014. To be eligible for inclusion, cervical cancer survivors had to have no evidence of disease, be 18 years of age, be able to understand Korean, and had to have engaged in sexual activity within 3 months of the study. Women who had not been diagnosed with any type of cancer in their medical records and who had engaged in sexual activity within the previous 3 months were assigned to the control group. Those who refused to participate or failed to complete the questionnaires were excluded.

Enrolled women's demographic data, including age, education, family income, marital status, and occupational status, were collected by interview and review of the medical records. Women's QoL was assessed using the European Organization for Research and Treatment of Cancer Quality of Life Questionnaire Core 30 (EORTC QLQ-C30) and Cervical Cancer module (EORTC QLQ-CX24).

The EORTC QLQ-C30 is a 30 item, cancer-specific questionnaire for assessment of five functioning scales (physical, role, emotional, cognitive, and social functions), three symptom scales (fatigue, pain, and nausea and vomiting), a scale for global health status and overall QoL, and six single-items (dyspnea, insomnia, appetite loss, constipation, diarrhea, and financial difficulties) [9]. The scales and single-item measures are scored from 0 to 100. In the functional and global health scales, higher scores indicate better functioning or status, while higher scores on the symptom scales and for the single-items reflect more problematic symptoms.

The EORTC QLQ-CX24 is a 24 item, cervical cancer-specific questionnaire composed of three multi-item scales (symptom experience, body image, and sexual/vaginal functioning) and six single-item scales (lymphedema, peripheral neuropathy, menopausal symptoms, sexual activity, sexual worry, and sexual enjoyment) [10]. The scales and singleitem measures are also scored from 0 to 100 . In sexual activity and sexual enjoyment, higher scores indicate better functioning, however, in the other scales and single-items, higher scores reflect more problematic functioning or status.

For assessment of women's sexual functioning, the Korean version of the Female Sexual Function Index (FSFI) was also used [11]. This 19-item questionnaire includes six domains: desire, arousal, lubrication, orgasm, satisfaction, and pain. A higher score in each domain indicates better status.

Statistical analysis was performed using the R statistical software ver. 2.12.1 (R Foundation for Statistical Computing, Vienna, Austria; ISBN 3-900051-07-0; http://www.Rproject. org). Because the demographic characteristics of the cervical cancer survivors and control groups were different, the two groups were matched in age, education, family income, marital status, occupational status, and exercise using propensity score matching. Count percentage, and quartile were used for analysis of the demographic and clinical characteristics of the participants. $t$ tests were performed for comparison of continuous variables between cervical cancer survivors and control groups.

\section{Results}

Among the women who agreed to participate in the study, 135 cervical cancer survivors and 220 women in the control group provided informed consent and completed the questionnaires (Fig. 1). After the propensity score matching, demographic data, including age, education, family income, marital status, occupational status, and regular exercise were not significantly different between the cervical cancer survivors and control group (Table 1).

The clinical characteristics of cervical cancer survivors are shown in Table 2. The majority of cervical cancer survivors (95.2\%) were International Federation of Gynecology and Obstetrics stage I and II diseases. Squamous cell carcinoma was the most frequent histologic type $(77.9 \%)$. The median interval from the diagnosis of cervical cancer to the current study was 45 months (range, 5 to 211 months). The proportions of the survivors according to the intervals between diagnosis to survey were as follows: $<2$ years, 29.8\%; $2-5$ years, $37.5 \%$; and $>5$ years, $32.7 \%$.

In terms of the treatment, radical hysterectomy was performed in $63.5 \%$ of the cervical cancer patients. Twelve point five percent of the survivors received all three treatment modalities: radical hysterectomy, radiotherapy, and chemotherapy. 


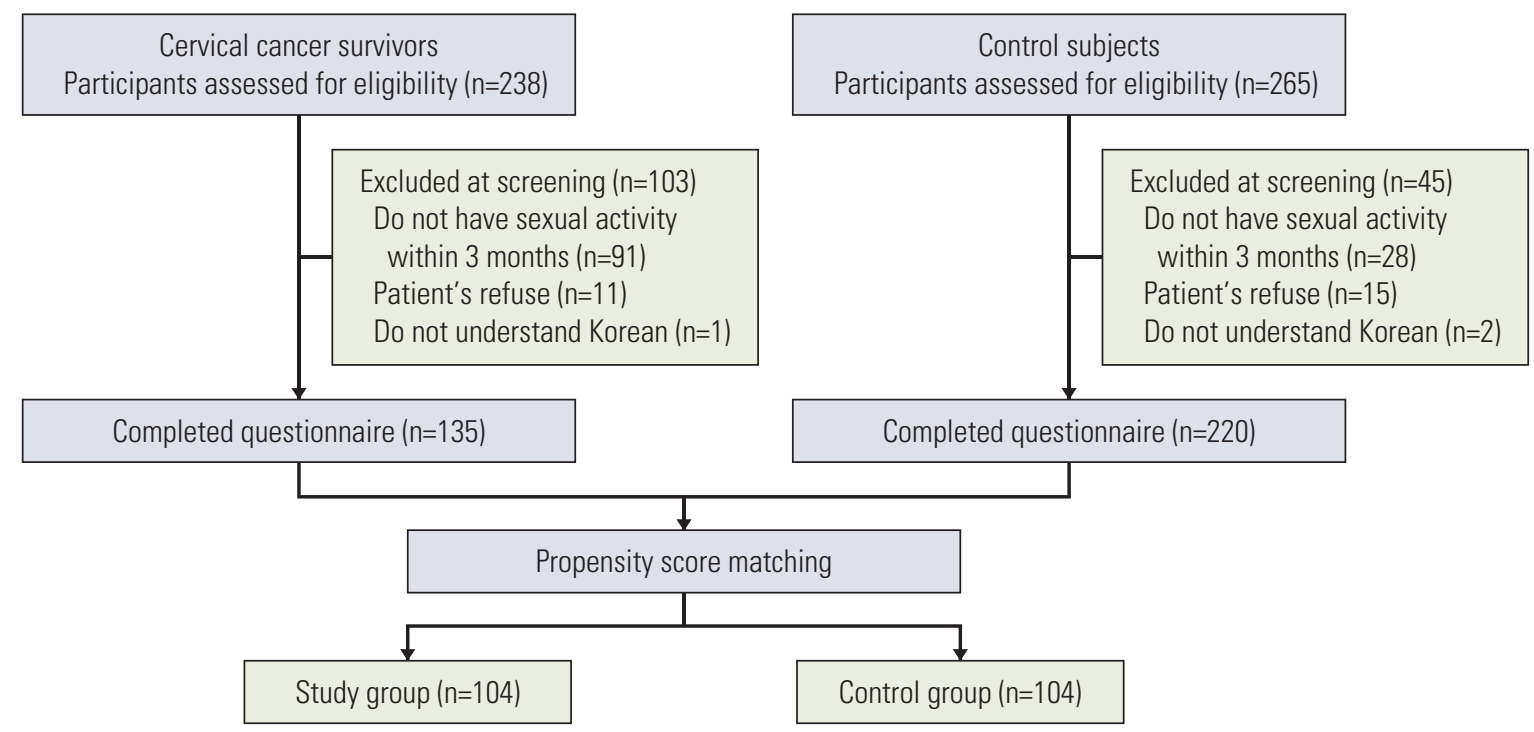

Fig. 1. Flow chart of enrollment.

Table 1. Demographic characteristics of cervical cancer survivors and control group

\begin{tabular}{|c|c|c|c|}
\hline Characteristic & Cervical cancer survivor $(\mathrm{n}=104)$ & Control group $(\mathrm{n}=104)$ & p-value \\
\hline Age (yr) & $46.95 \pm 7.98$ & $48.86 \pm 8.53$ & 0.098 \\
\hline \multicolumn{4}{|l|}{ Marital status } \\
\hline Single/Separated/Widowed & $14(13.5)$ & $11(10.6)$ & 0.670 \\
\hline Married & $90(86.5)$ & $93(89.4)$ & \\
\hline \multicolumn{4}{|l|}{ Education (yr) } \\
\hline$\leq 9$ & $12(11.5)$ & $14(13.5)$ & 0.834 \\
\hline$>9$ & $92(88.5)$ & $90(86.5)$ & \\
\hline \multicolumn{4}{|l|}{ Family income (\$/mo) } \\
\hline$\leq 2,000$ & $13(12.5)$ & $16(15.4)$ & 0.833 \\
\hline$>2,000$ to $\leq 4,000$ & $45(43.3)$ & $44(42.3)$ & \\
\hline$>4,000$ & $46(44.2)$ & $44(42.3)$ & \\
\hline \multicolumn{4}{|l|}{ Occupational status } \\
\hline Yes & $45(43.3)$ & $49(47.1)$ & 0.676 \\
\hline No & $59(56.7)$ & $55(52.9)$ & \\
\hline \multicolumn{4}{|l|}{ Menopause status } \\
\hline Yes & $76(73.1)$ & $67(64.4)$ & 0.231 \\
\hline No & $28(26.9)$ & $37(35.6)$ & \\
\hline \multicolumn{4}{|l|}{ Regular exercise } \\
\hline Yes & $50(48.1)$ & $45(43.3)$ & 0.578 \\
\hline No & $54(51.9)$ & $59(56.7)$ & \\
\hline
\end{tabular}

Values are presented as mean \pm standard deviation or number $(\%)$.

The comparison of the EORTC QLQ-C30 and CX24 scores between cervical cancer survivors and control group is shown in Table 3. Among the scales, only scores for lymphedema (mean, 20.2 vs. 12.2; $\mathrm{p}=0.022$ ) and body image (mean, 73.1 vs. 79.6; $\mathrm{p}=0.036$ ) were significantly different between the two groups. When the scale of sexual/vaginal functioning in EORTC QLQ-CX24 was divided into individual questions, cervical cancer survivors reported shorter 
Table 2. Clinical characteristics of cervical cancer survivors

\begin{tabular}{|c|c|}
\hline Characteristic & $\begin{array}{l}\text { Cervical cancer survivor } \\
\qquad(\mathrm{n}=104)\end{array}$ \\
\hline \multicolumn{2}{|l|}{ FIGO stage } \\
\hline I & $81(77.9)$ \\
\hline II & $18(17.3)$ \\
\hline III & $4(3.8)$ \\
\hline IV & $1(1.0)$ \\
\hline \multicolumn{2}{|l|}{ Histology } \\
\hline Squamous cell carcinoma & $81(77.9)$ \\
\hline Adenocarcinoma & $22(21.2)$ \\
\hline Small cell carcinoma & $1(1.0)$ \\
\hline \multicolumn{2}{|l|}{ Survival period (yr) } \\
\hline$\leq 2$ & $31(29.8)$ \\
\hline$>2$ to $\leq 5$ & $39(37.5)$ \\
\hline$>5$ & $34(32.7)$ \\
\hline \multicolumn{2}{|l|}{ Type of treatment } \\
\hline Conization only & $14(13.5)$ \\
\hline Simple hysterectomy only & $8(7.7)$ \\
\hline Radical hysterectomy only & $43(41.3)$ \\
\hline Conization $+\mathrm{R}+\mathrm{C}$ & $2(1.9)$ \\
\hline Simple hysterectomy+C & $1(1.0)$ \\
\hline Simple hysterectomy $+\mathrm{R}+\mathrm{C}$ & $2(1.9)$ \\
\hline Radical hysterectomy+C & $4(3.8)$ \\
\hline Radical hysterectomy+R & $6(5.8)$ \\
\hline Radical hysterectomy $+\mathrm{R}+\mathrm{C}$ & $13(12.5)$ \\
\hline Staging surgery only $+\mathrm{R}$ & $3(2.9)$ \\
\hline R only & $1(1.0)$ \\
\hline $\mathrm{R}+\mathrm{C}$ & $7(6.7)$ \\
\hline \multicolumn{2}{|l|}{ Type of surgery } \\
\hline Conization & $16(15.4)$ \\
\hline Simple hysterectomy & $11(10.6)$ \\
\hline Radical hysterectomy & $66(63.5)$ \\
\hline Staging surgery & $3(2.9)$ \\
\hline No surgery & $8(7.7)$ \\
\hline \multicolumn{2}{|l|}{ Status of ovaries } \\
\hline Ovaries in situ & $79(76.0)$ \\
\hline Ovarian transposition & $1(1.0)$ \\
\hline Bilateral oophorectomy & $18(17.3)$ \\
\hline Unilateral oophorectomy & $6(5.8)$ \\
\hline
\end{tabular}

Values are presented as number (\%). Staging surgery was defined as performance of pelvic lymphadenectomy and para-aortic lymphadenectomy without hysterectomy. FIGO, International Federation of Gynecology and Obstetrics; $R$, radiotherapy; $C$, chemotherapy. vaginal length than the control group, but without statistical significance (mean, 80.6 vs. 85.4; $\mathrm{p}=0.077$ ). Other scale scores of the EORTC QLQ-CX24 including sexual activity (32.1 vs. $30.1, \mathrm{p}=0.583$ ), sexual enjoyment ( 40.1 vs. $37.8, \mathrm{p}=0.537$ ), and sexual worry ( 26.6 vs. $22.0, \mathrm{p}=0.214$ ) were similar between cervical cancer survivors and control group.

The comparison of the FSFI scores between two groups is also shown in Table 3. Scale scores for desire (3.0 vs. 2.9, $\mathrm{p}=0.617$ ), arousal ( $3.5 \mathrm{vs.} 3.2, \mathrm{p}=0.232$ ), lubrication (4.1 vs. 4.0, $\mathrm{p}=0.696$ ), orgasm (3.9 vs. 3.7, $\mathrm{p}=0.356)$, satisfaction (4.0 vs. $3.9, \mathrm{p}=0.363$ ), and pain ( 4.5 vs. $4.1, \mathrm{p}=0.214$ ) were not significantly different between cervical cancer survivors and control group.

\section{Discussion}

In the current study, lymphedema was more problematic in cervical cancer survivors compared to the control group. Sexuality, both in terms of sexual activity, sexual enjoyment, and sexual worry (EORTC QLQ-CX24), and in terms of desire, arousal, lubrication, orgasm, satisfaction, and pain (FSFI) were similar between the two groups.

Data from previously published studies on cervical cancer survivors' sexuality which used the FSFI are summarized in Table 4 [12-17]. Sexual functioning deteriorated after radiotherapy, radical hysterectomy, and radical trachelectomy [14-16]. Older age and lower level of education were associated with more deteriorated sexual functioning of the survivors [17]. Importantly, impact of the type of treatment on sexuality was inconsistent among the previous studies [12, 14]. In the current study, with 45 months of median interval from the diagnosis, cervical cancer survivors showed similar total FSFI scores compared to the control group (23.0 vs. 21.9, $\mathrm{p}=0.300$ ).

It has been reported that survivors of gynecologic malignancies express a reluctance to engage in sexual activity due to the fear of recurrence [18]. In the current study, the proportion of women excluded because of absence of sexual activity within 3 months was $38.2 \%(91 / 238)$ in cervical cancer survivors, whereas it was only $10.6 \%(28 / 265)$ in the control group. In addition, as Asians are known to be more sexually conservative, Korean women are considered to have relatively lower levels of sexual interest and activity [19]. These features might result in similar sexual functioning between cervical cancer survivors and control group.

In the current study, the target participants were limited to women who had engaged in sexual activity within 3 months. Although the diagnosis of sexual dysfunction is usually evaluated sexual problems within the last 6 months at 
Table 3. Comparison of quality of life and sexual function between cervical cancer survivors and control group

\begin{tabular}{|c|c|c|c|}
\hline Domain & Cervical cancer survivor $(\mathrm{n}=104)$ & Control group ( $n=104)$ & p-value \\
\hline \multicolumn{4}{|l|}{ EORTC QLQ-C30 } \\
\hline Physical functioning & $79.3 \pm 15.5$ & $80.6 \pm 14.5$ & 0.539 \\
\hline Role functioning & $85.7 \pm 19.8$ & $87.3 \pm 17.1$ & 0.533 \\
\hline Emotional functioning & $77.9 \pm 20.9$ & $76.8 \pm 21.9$ & 0.706 \\
\hline Cognitive functioning & $77.9 \pm 17.6$ & $78.4 \pm 16.9$ & 0.841 \\
\hline Social functioning & $83.2 \pm 24.3$ & $88.1 \pm 21.1$ & 0.117 \\
\hline Fatigue & $35.1 \pm 22.7$ & $39.9 \pm 23.9$ & 0.147 \\
\hline Nausea and vomiting & $5.8 \pm 13.3$ & $8.7 \pm 16.9$ & 0.173 \\
\hline Pain & $15.2 \pm 19.6$ & $19.4 \pm 21.7$ & 0.147 \\
\hline Dyspnea & $12.2 \pm 20.8$ & $12.8 \pm 19.9$ & 0.820 \\
\hline Insomnia & $23.4 \pm 27.8$ & $25.3 \pm 26.9$ & 0.613 \\
\hline Appetite loss & $11.2 \pm 19.5$ & $10.3 \pm 18.0$ & 0.712 \\
\hline Constipation & $25.0 \pm 28.2$ & $21.8 \pm 28.5$ & 0.416 \\
\hline Diarrhea & $14.7 \pm 21.2$ & $11.9 \pm 22.2$ & 0.339 \\
\hline Financial difficulties & $11.2 \pm 20.6$ & $10.3 \pm 21.3$ & 0.741 \\
\hline Global health status & $64.5 \pm 20.2$ & $59.9 \pm 20.5$ & 0.108 \\
\hline \multicolumn{4}{|l|}{ EORTC QLQ-CX24 } \\
\hline Body image & $73.1 \pm 25.2$ & $79.6 \pm 18.8$ & 0.036 \\
\hline Symptom experience & $12.1 \pm 10.1$ & $10.5 \pm 8.9$ & 0.244 \\
\hline Lymphedema & $20.2 \pm 28.0$ & $12.2 \pm 21.8$ & 0.022 \\
\hline Peripheral neuropathy & $22.4 \pm 28.4$ & $17.0 \pm 23.2$ & 0.132 \\
\hline Menopausal symptoms & $20.5 \pm 27.2$ & $17.3 \pm 23.2$ & 0.362 \\
\hline Sexual activity & $32.1 \pm 24.5$ & $30.1 \pm 26.6$ & 0.583 \\
\hline Sexual enjoyment & $40.1 \pm 24.3$ & $37.8 \pm 25.9$ & 0.537 \\
\hline Sexual/Vaginal functioning & $80.6 \pm 20.6$ & $85.4 \pm 16.8$ & 0.077 \\
\hline Sexual worry & $26.6 \pm 28.0$ & $22.0 \pm 24.9$ & 0.214 \\
\hline \multicolumn{4}{|l|}{ FSFI } \\
\hline Desire & $3.0 \pm 1.0$ & $2.9 \pm 1.1$ & 0.617 \\
\hline Arousal & $3.5 \pm 1.3$ & $3.2 \pm 1.6$ & 0.232 \\
\hline Lubrication & $4.1 \pm 1.7$ & $4.0 \pm 1.9$ & 0.696 \\
\hline Orgasm & $3.9 \pm 1.5$ & $3.7 \pm 1.8$ & 0.356 \\
\hline Satisfaction & $4.0 \pm 0.7$ & $3.9 \pm 1.2$ & 0.363 \\
\hline Pain & $4.5 \pm 1.7$ & $4.1 \pm 2.0$ & 0.214 \\
\hline Total & $23.0 \pm 6.6$ & $21.9 \pm 8.2$ & 0.300 \\
\hline
\end{tabular}

Values are presented as mean \pm standard deviation. EORTC QLQ-C30, The European Organization for Research and Treatment of Cancer Quality of Life Questionnaire-Core 30; EORTC QLQ-CX24, The European Organization for Research and Treatment of Cancer Quality of Life Questionnaire-Cervical Cancer Module; FSFI, Female Sexual Function Index.

DSM-5, the Japanese researchers who developed the Japanese version of the FSFI proposed sexual activity within 3 months [20]. Accordingly, women who had sexual activity within 3 months, rather than 6 months, were enrolled in this study.

The QoL of cervical cancer survivors has improved over time [21]. A similar level of QoL between cervical cancer survivors and control groups may be explained by the relatively long interval from the diagnosis to the survey (median, 45 months), as well as by the survivors' disease-free state.
Body image is a part of the QoL. The majority of rectal, gastric, and head and neck cancer patients have shown a deteriorated body image $[22,23]$. The aggravated body image during cancer treatment may recover gradually after treatment. However, body image is often not fully recovered, even 5 years after treatment [23]. Body image is also known to be affected by socioeconomic status.

Interestingly, the cervical cancer survivors in the current study showed better body image than women in the control group (73.1 vs. 79.6, $\mathrm{p}=0.036$ ). Possible reasons for this find- 


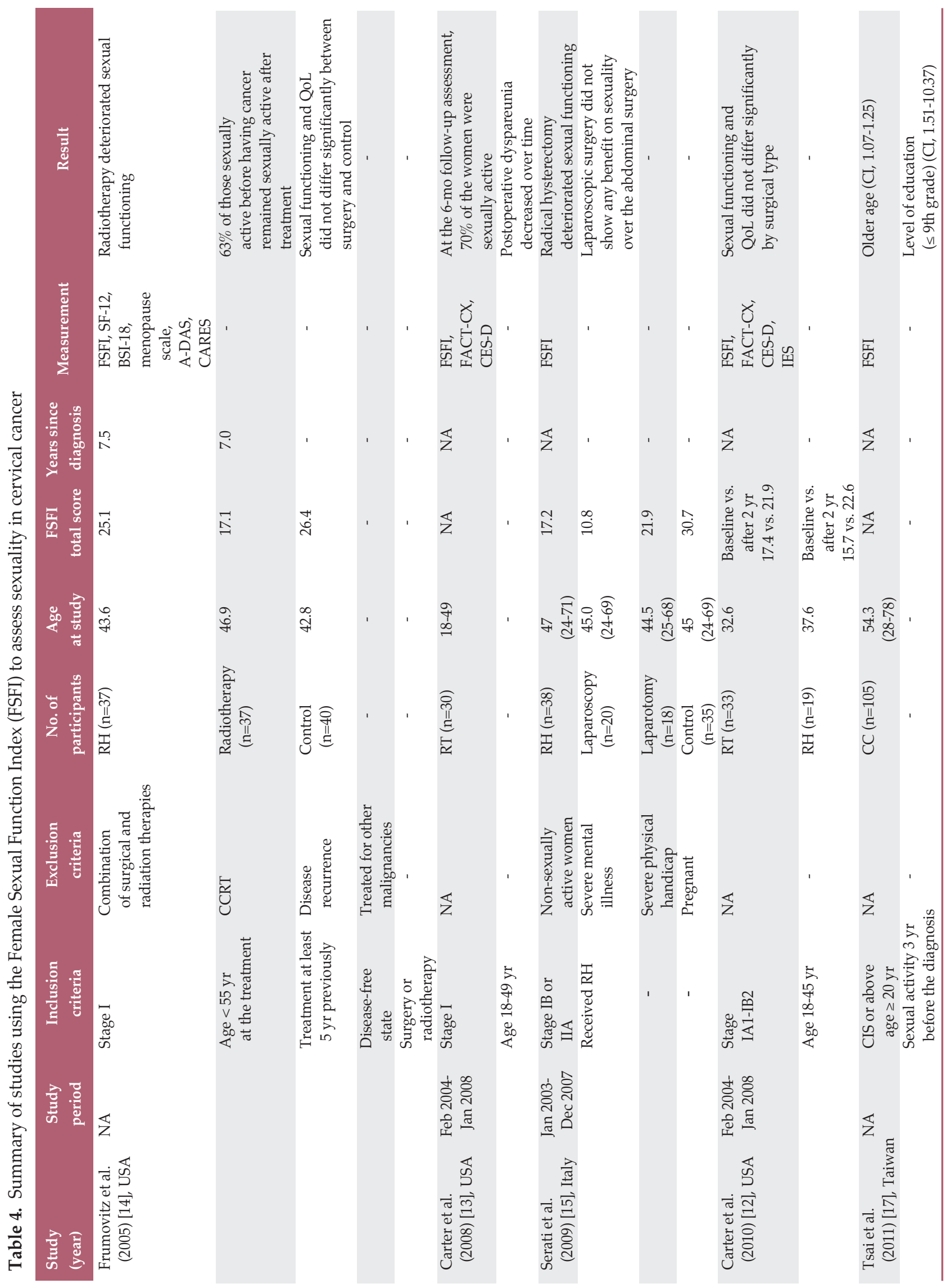




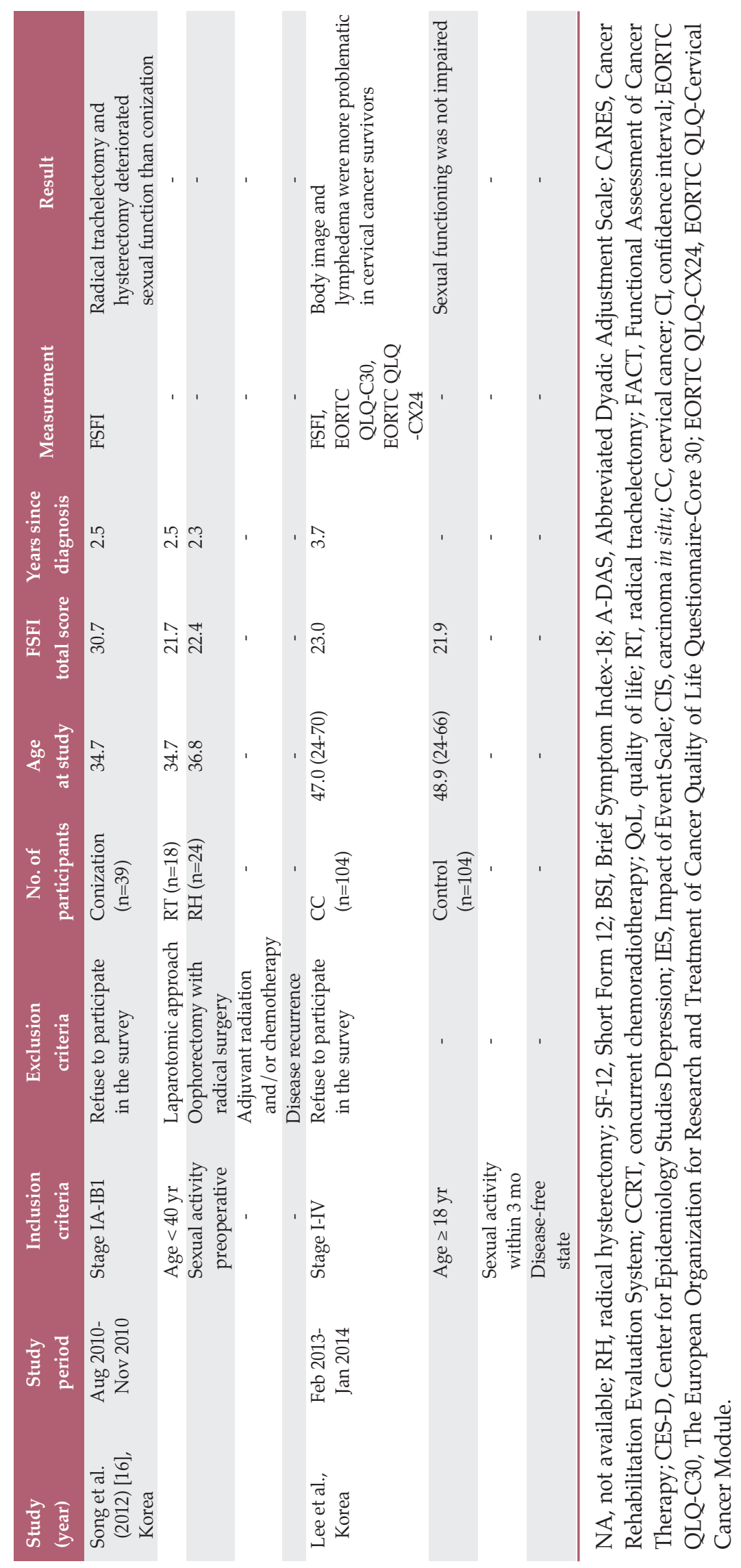


ing may be as follows. (1) Through the three concise questions for measurement of body image, quantitative or detailed measurement of body image was limited. (2) Korean women tend to be sensitive regarding their appearance and to have more body dissatisfaction. According to the previous study comparing body satisfaction across groups of college women from Korea, China, and the United States, the highest dissatisfaction was observed in Korean women [24]. In the Korea National Health and Nutrition Examination Survey, 2007-2010, a quarter of underweight adult Korean women (25.4\%) have tried to control weight, and this attempt was influenced by distorted body image [25]. Therefore, even Korean women who are healthy and without disease may have poor body image. (3) Last, because of propensity score matching, socioeconomic status, known to be associated with altered body image, was not different between the two groups.

The symptoms of lymphedema were aggravated in cervical cancer survivors compared to the control group, as treatment for cervical cancer includes pelvic lymph node dissection as part of surgical treatment, chemotherapy, or radiotherapy in the pelvic area. After surgery and radiotherapy, a damaged lymphatic system is not fully recovered. The prolonged or persistent lymphedema-related symptoms have been also known to cause deterioration of the patients' QoL [21].

The current study had several limitations. Only women who had engaged in sexual activity within 3 months were included. Propensity score matching was used to make an adjustment for demographic characteristics of the cervical cancer survivors and control group. Inevitable issues, such as selection bias, might exist in this case-control study.

\section{Conclusion}

Compared with healthy women, sexual functioning was not impaired in cervical cancer survivors who showed no evidence of disease after primary treatment and engaging in sexual activity. However, in terms of QoL, lymphedema was more problematic in cervical cancer survivors than in the control group. Prospective cohort studies are warranted to confirm these findings.

\section{Conflicts of Interest}

Conflict of interest relevant to this article was not reported.

\section{Acknowledgments}

This work was supported by grants from the Korean National Cancer Center (1340930-1).

\section{References}

1. Jung KW, Won YJ, Oh CM, Kong HJ, Cho H, Lee DH, et al. Prediction of cancer incidence and mortality in Korea, 2015. Cancer Res Treat. 2015;47:142-8.

2. Lim MC, Moon EK, Shin A, Jung KW, Won YJ, Seo SS, et al. Incidence of cervical, endometrial, and ovarian cancer in Korea, 1999-2010. J Gynecol Oncol. 2013;24:298-302.

3. Park SY, Bae DS, Nam JH, Park CT, Cho CH, Lee JM, et al. Quality of life and sexual problems in disease-free survivors of cervical cancer compared with the general population. Cancer. 2007;110:2716-25.

4. Choi J, Shin DW, Lee S, Jeon MJ, Kim SM, Cho B, et al. Doseresponse relationship between cigarette smoking and female sexual dysfunction. Obstet Gynecol Sci. 2015;58:302-8.

5. Lee Y, Lim MC, Son Y, Joo J, Park K, Kim JS, et al. Development and evaluation of Korean version of Quality of Sexual Function (QSF-K) in healthy Korean women. J Korean Med
Sci. 2014;29:758-63.

6. Lee Y, Lim MC, Joo J, Park K, Lee S, Seo S, et al. Development and validation of the Korean version of the Female Sexual Function Index-6 (FSFI-6K). Yonsei Med J. 2014;55:1442-6.

7. Kim SI, Lee Y, Lim MC, Joo J, Park K, Lee DO, et al. Quality of life and sexuality comparison between sexually active ovarian cancer survivors and healthy women. J Gynecol Oncol. 2015; 26:148-54.

8. Vistad I, Fossa SD, Dahl AA. A critical review of patient-rated quality of life studies of long-term survivors of cervical cancer. Gynecol Oncol. 2006;102:563-72.

9. Yun YH, Park YS, Lee ES, Bang SM, Heo DS, Park SY, et al. Validation of the Korean version of the EORTC QLQ-C30. Qual Life Res. 2004;13:863-8.

10. Shin DW, Ahn E, Kim YM, Kang S, Kim BG, Seong SJ, et al. Cross-cultural application of the Korean version of the Euro- 
pean Organization for Research and Treatment of Cancer quality of life questionnaire cervical cancer module. Oncology. 2009;76:190-8.

11. Kim HY, So HS, Park KS, Jeong SJ, Lee JY, Ryu SB. Development of the Korean-version of Female Sexual Function Index (FSFI). Korean J Androl. 2002;20:50-6.

12. Carter J, Sonoda Y, Baser RE, Raviv L, Chi DS, Barakat RR, et al. A 2-year prospective study assessing the emotional, sexual, and quality of life concerns of women undergoing radical trachelectomy versus radical hysterectomy for treatment of earlystage cervical cancer. Gynecol Oncol. 2010;119:358-65.

13. Carter J, Sonoda Y, Chi DS, Raviv L, Abu-Rustum NR. Radical trachelectomy for cervical cancer: postoperative physical and emotional adjustment concerns. Gynecol Oncol. 2008;111: 151-7.

14. Frumovitz M, Sun CC, Schover LR, Munsell MF, Jhingran A, Wharton JT, et al. Quality of life and sexual functioning in cervical cancer survivors. J Clin Oncol. 2005;23:7428-36.

15. Serati M, Salvatore S, Uccella S, Laterza RM, Cromi A, Ghezzi $\mathrm{F}$, et al. Sexual function after radical hysterectomy for earlystage cervical cancer: is there a difference between laparoscopy and laparotomy? J Sex Med. 2009;6:2516-22.

16. Song T, Choi CH, Lee YY, Kim TJ, Lee JW, Kim BG, et al. Sexual function after surgery for early-stage cervical cancer: is there a difference in it according to the extent of surgical radicality? J Sex Med. 2012;9:1697-704.

17. Tsai TY, Chen SY, Tsai MH, Su YL, Ho CM, Su HF. Prevalence and associated factors of sexual dysfunction in cervical cancer patients. J Sex Med. 2011;8:1789-96.

18. Reis N, Beji NK, Coskun A. Quality of life and sexual function- ing in gynecological cancer patients: results from quantitative and qualitative data. Eur J Oncol Nurs. 2010;14:137-46.

19. Nicolosi A, Glasser DB, Kim SC, Marumo K, Laumann EO; GSSAB Investigators' Group. Sexual behaviour and dysfunction and help-seeking patterns in adults aged 40-80 years in the urban population of Asian countries. BJU Int. 2005;95:60914.

20. Takahashi M, Inokuchi T, Watanabe C, Saito T, Kai I. The Female Sexual Function Index (FSFI): development of a Japanese version. J Sex Med. 2011;8:2246-54.

21. Mantegna G, Petrillo M, Fuoco G, Venditti L, Terzano S, Anchora LP, et al. Long-term prospective longitudinal evaluation of emotional distress and quality of life in cervical cancer patients who remained disease-free 2-years from diagnosis. BMC Cancer. 2013;13:127.

22. Li X, Song X, Chen Z, Li M, Lu L, Xu Y, et al. Quality of life in rectal cancer patients after radical surgery: a survey of Chinese patients. World J Surg Oncol. 2014;12:161.

23. Lee SS, Chung HY, Kwon OK, Yu W. Quality of life in cancer survivors 5 years or more after total gastrectomy: a case-control study. Int J Surg. 2014;12:700-5.

24. Jung J, Forbes GB. Body dissatisfaction and disordered eating among college women in China, South Korea, and the United States: Contrasting predictions from sociocultural and feminist theories. Psychol Women Q. 2007;31:381-93.

25. Choi OJ, Cho YG, Kang JH, Park HA, Kim KW, Hur YI, et al. Weight control attempts in underweight korean adults: Korea national health and nutrition examination survey, 2007-2010. Korean J Fam Med. 2013;34:393-402. 